\title{
Self-Assembly of Nanoparticles in a Modular Fashion to Prepare Multifunctional Catalysts for Cascade Reactions: From Simplicity to Complexity
}

\author{
Danjie Li, ${ }^{\dagger}$ Lingmei Liu, ${ }^{\S}$ Lijing Zhang, ${ }^{\dagger}$ Shengyang Tao, ${ }^{*}{ }^{\dagger}$ Guangtao Li, ${ }^{\ddagger}$ Y Yongxian Yu, ${ }^{\dagger}$ \\ and Xin Liu ${ }^{\dagger}$ \\ ${ }^{\dagger}$ Department of Chemistry, Dalian University of Technology, Dalian 116024, Liaoning, China \\ ${ }^{*}$ Department of Chemistry, Tsinghua University, Beijing 100084, China \\ ${ }^{\S}$ Center of Advanced Membranes and Porous Materials, Division of Physical Science and Engineering, King Abdullah University of \\ Science and Technology, Jeddah 21589, Kingdom of Saudi Arabia
}

\section{Supporting Information}

ABSTRACT: One-pot cascade reactions can simplify the synthetic route and reduce the use of solvents and energy. The critical part of the completion of the cascade reaction is the preparation of multifunctional catalysts. In this work, a novel and simple pathway was developed to construct multifunctional catalysts with acidic, basic, and magnetic properties at the same time. Mesoporous silica materials modified with different metal oxides were used as catalytic elements. Microspheres that assembled with catalytic components have a diameter of $150 \mu \mathrm{m}$ and a specific surface area larger than $400 \mathrm{~m}^{2} \mathrm{~g}^{-1}$ and can be used as catalysts for cascade reactions.

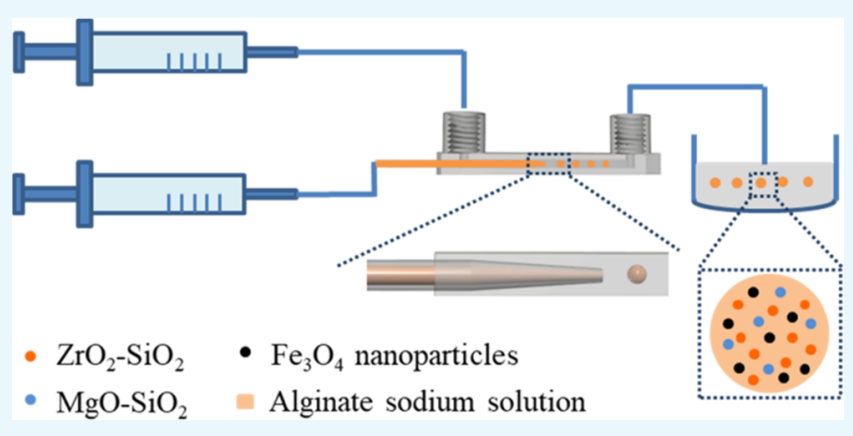
The yield of the final product in the deacetalizationKnoevenagel reaction is $92 \%$. Microspheres integrated with $\mathrm{Fe}_{3} \mathrm{O}_{4}$ nanoparticles have a magnetic susceptibility of 7.2 emu $\mathrm{g}^{-1}$ and can be easily removed from the reaction system by applying an external magnetic field. This multimodule assembly method fully reflects the enormous power of complexity resulting from simplicity. This method provides a reference and practical technical support for the preparation of other multifunctional materials.

\section{INTRODUCTION}

Catalysts for one-pot cascade reactions have attracted great interest in catalysis these years. ${ }^{1-10}$ Designed cascade reactions can simplify the synthetic route and reduce the use of solvents and energy. The critical part of completing these kinds of reactions is multifunctional catalysts, which contain various catalytic active sites for different steps. ${ }^{11-16}$ Therefore, researchers make various attempts to develop catalysts having both acidic and basic catalytic sites for heterogeneous catalytic reactions. $^{17-22}$

Various procedures have been developed to achieve an acid-base bifunctional catalyst. ${ }^{23-27}$ For example, some researchers modify porous polymers ${ }^{28}$ or silica material ${ }^{29}$ with organic acidic and basic groups, such as amino, pyridyl, carboxyl, or sulfonyl groups. The others combine inorganic compounds with opposite acidity and alkalinity together. ${ }^{30}$ As a derivation of the above two methods, organic acids or bases are also matched to inorganic ones. However, most of these approaches need to anchor catalytic sites to the substrate step by step. Sophisticated and delicate operations are usually essential for the fabrication of the catalyst to prevent the interference during the immobilization of the acid and base.
Therefore, it is necessary to find a new approach to develop acid-base catalysts.

In cells, enzymes for various chemical reactions are stored in different organelles. Organelles are included in one capsule to complete cascade reactions. This mode of operation makes cells similar to a mini chemical plant. Each organelle plays the role of one unit operation and does not disturb others. Inspired by the feature of cells, herein, we report a novel and simple pathway to construct multifunctional catalysts with acidic, basic, and magnetic properties at the same time for the cascade reaction. The trifunctional catalyst is prepared via the selfassembly of nanoparticles in microfluidic chips in a modular fashion. The microfluidic chip is a powerful tool to produce uniform microspheres with controllable diameters and components. ${ }^{31-38}$ Mesoporous silica particles with acidic and basic properties are coassembled with magnetic nanosized $\mathrm{Fe}_{3} \mathrm{O}_{4}$. The sodium alginate cross-links these nanoparticles in microdroplets. Acidic and basic mesoporous materials take charge of catalyzing the deacetalization-Knoevenagel reaction,

Received: November 6, 2018

Accepted: January 8, 2019

Published: January 17, 2019 

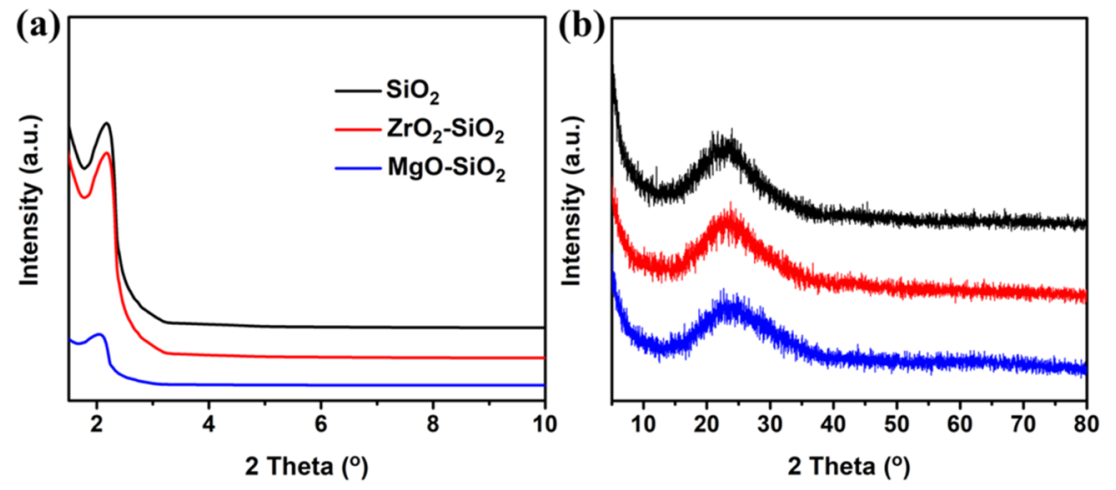

Figure 1. (a) Low-angle and (b) high-angle XRD patterns of mesoporous silica materials.
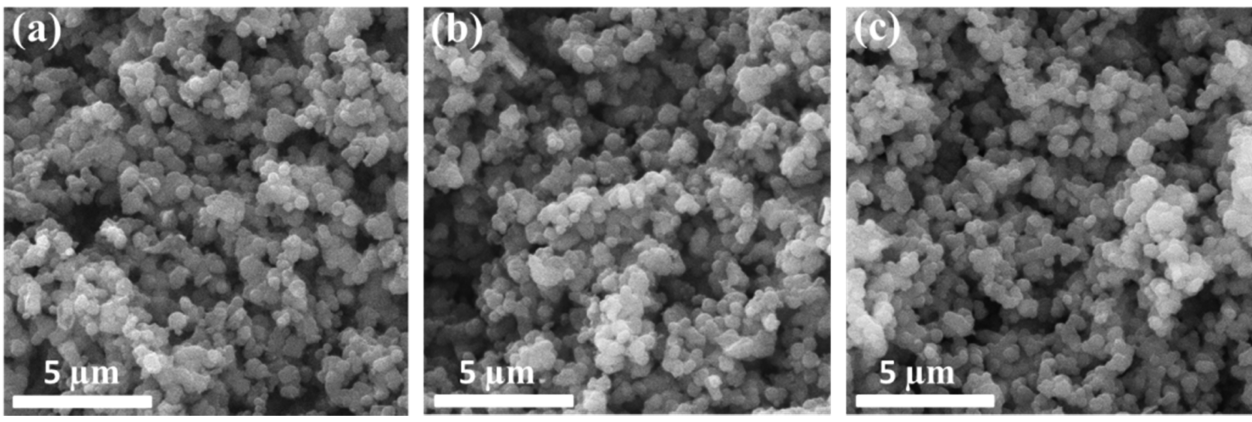

Figure 2. SEM images of (a) unmodified mesoporous silica, (b) zirconium dioxide-modified mesoporous silica $\left(\mathrm{ZrO}_{2}-\mathrm{SiO}_{2}\right)$, and $(\mathrm{c})$ magnesium oxide-modified mesoporous silica $\left(\mathrm{MgO}-\mathrm{SiO}_{2}\right)$.
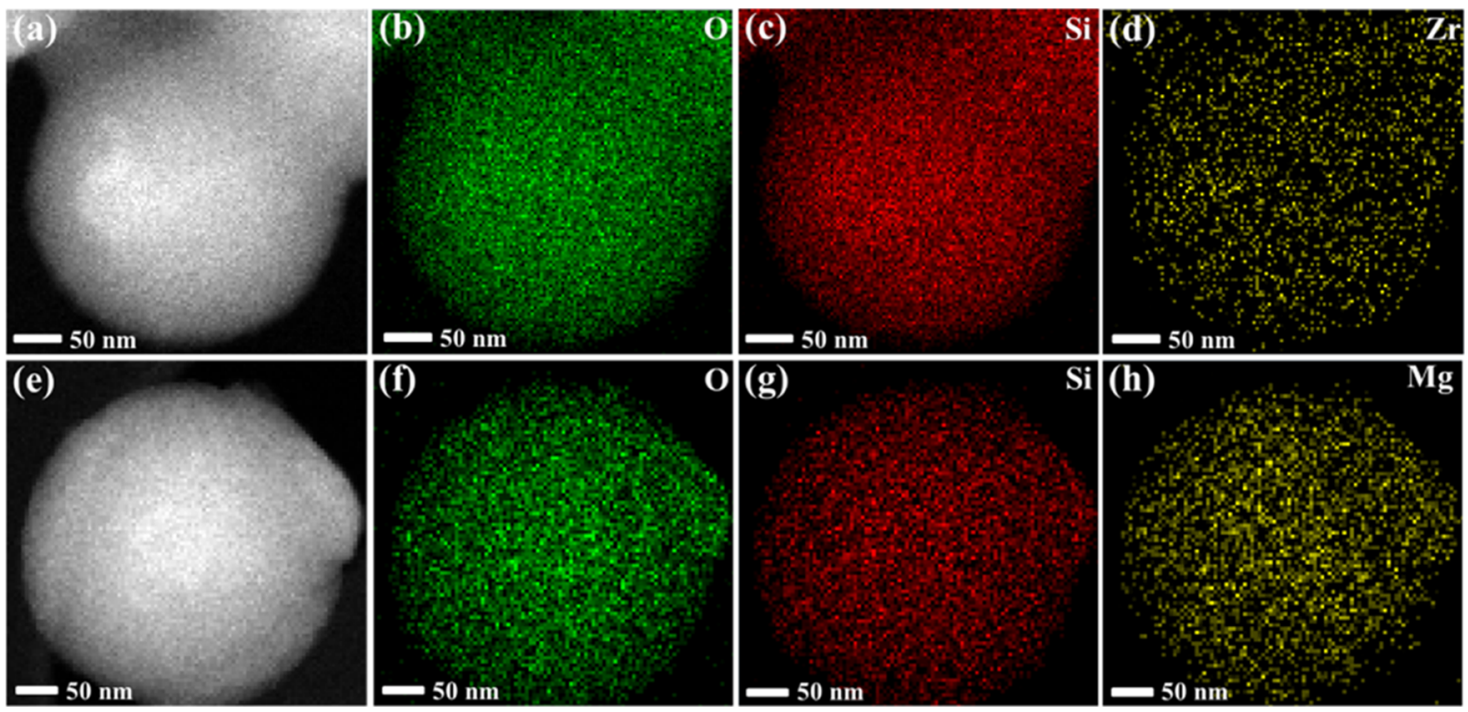

Figure 3. Transmission electron microscopy (TEM) images and energy-dispersive X-ray spectroscopy (EDX) mapping of mesoporous silica materials. (a, e) High-angle annular dark-field images of mesoporous silica and distribution of O (b, f), Si (e, g), Zr (d), and Mg (h).

which needs the acid-base cocatalyst to synthesize a lot of useful fine organic chemicals. Meanwhile, magnetic particles endow the catalyst the removable ability by an external magnetic field. Each kind of particle is one module for building the whole system of the catalyst. The particles perform their functions without interference, like unit operations in chemical plants or organelles in cells. The synthetic process of the catalyst is facile and does not use any volatile solvent. The catalysts exhibit excellent activity and selectivity and are easily reused several times by being recovered with the magnet.

\section{RESULTS AND DISCUSSION}

Both acidic and basic catalytic components were prepared using an impregnation calcination method. The X-ray diffraction (XRD) patterns of silica materials are shown in Figure 1. The prepared silica material has a significant diffraction peak at $2.18^{\circ}$, which is unique to the mesoporous structure, indicating that the pores of the material are nanosized.

After loading zirconium, the position of the diffraction peak shifts to a low angle and the diffraction intensity decreases, but the decrease is not significant. This means that a load of 

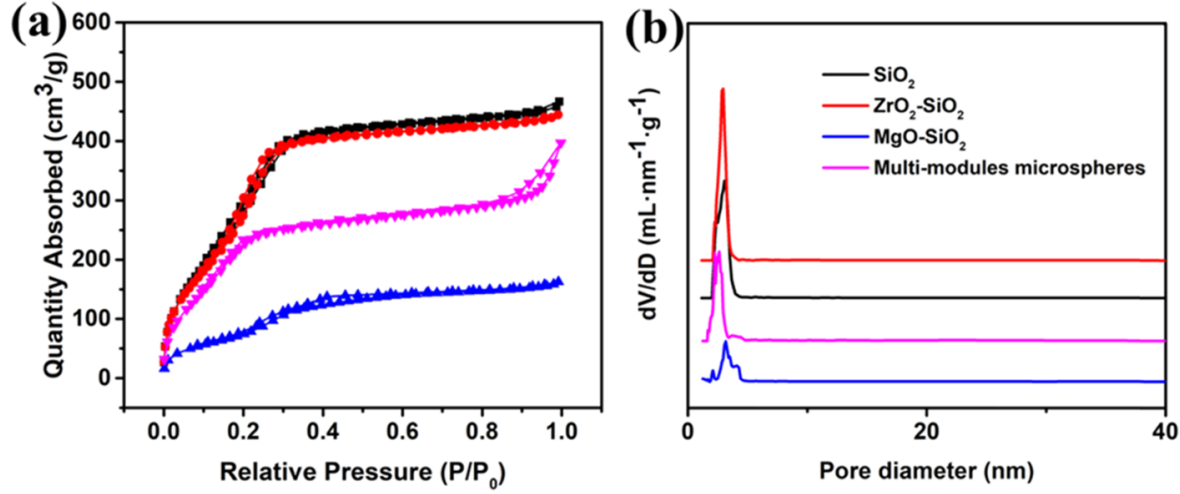

Figure 4. (a) Ar adsorption-desorption isotherms of the mesoporous silica materials and the multimodule microspheres and (b) pore size distribution of the mesoporous silica materials and the multimodule microspheres.
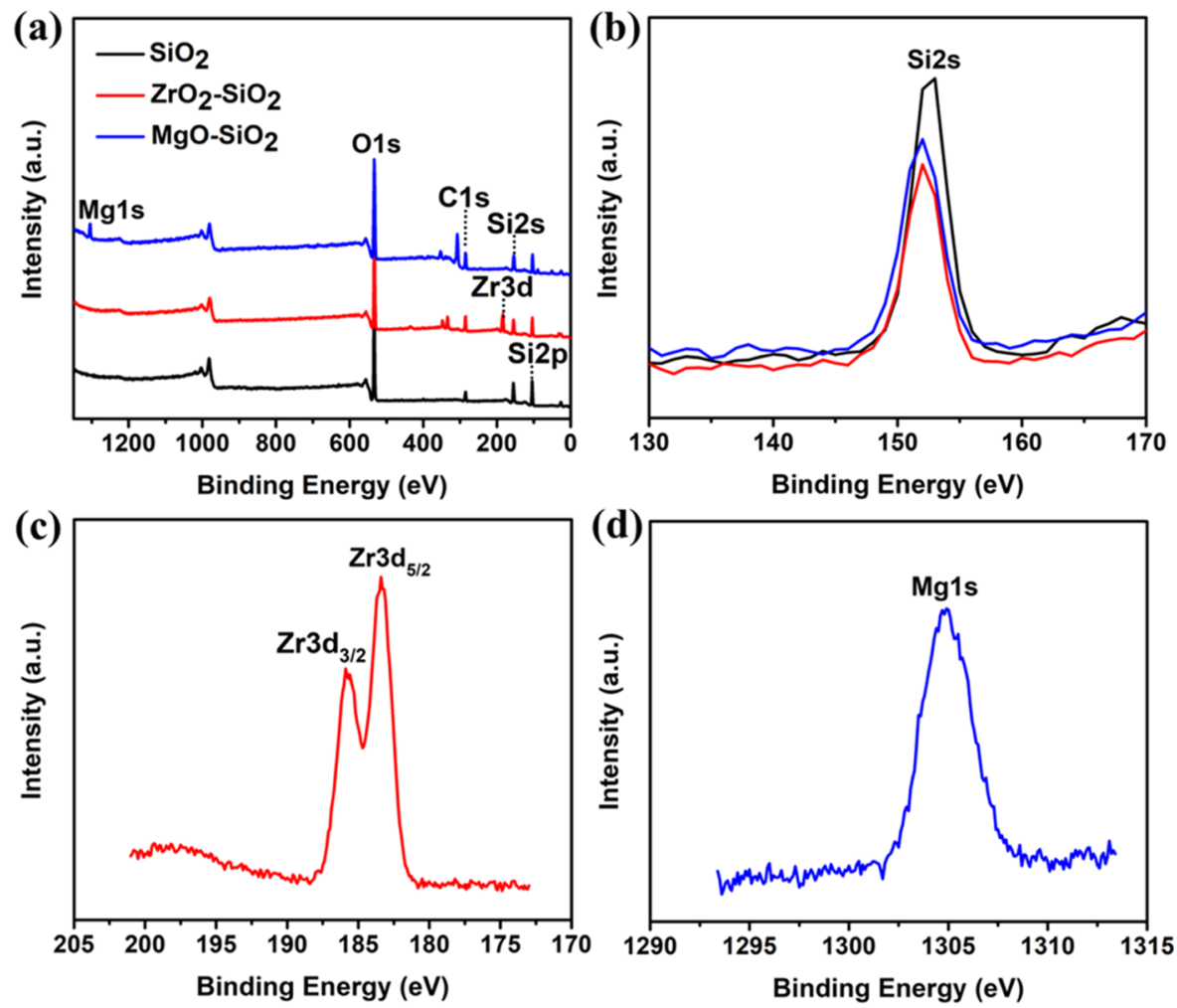

Figure 5. (a) XPS patterns of mesoporous silica materials, (b) Si 2 s spectra of mesoporous silica materials, (c) $\mathrm{Zr} 3 \mathrm{~d}$ spectra of $\mathrm{ZrO}_{2}-\mathrm{SiO}_{2}$, and (d) $\mathrm{Mg} 1 \mathrm{~s}$ spectra of $\mathrm{MgO}-\mathrm{SiO}_{2}$.

zirconia caused a decrease in pore size and that its mesoporous structure was well maintained. However, after loading magnesium oxide, the diffraction peak shifts to a high angle and the diffraction intensity decreases, which means that the internal pore diameter of the particles increases and the degree of mesoporous structure decreases. This may be because magnesium oxide is more basic and reacts with silica at high temperature, causing the pores to be partially destroyed. However, significant diffraction peaks can be observed at low diffraction angles, indicating that the mesoporous structure still exists in $\mathrm{MgO}-\mathrm{SiO}_{2}$. Only the disordered structure diffraction peaks can be observed at high angles (Figure 1b), without respective characteristic diffraction peaks of the metal oxides. This indicates that in the two types of composites the metal oxides are low in the content and not in the form of a crystal.
Scanning electron microscopic (SEM) images (Figure 2) also show that the mesoporous particles did not significantly change their spherical morphology before and after loading metal oxides. At the same time, free-existing oxide powders were not observed between the particles, indicating that the oxides mainly existed in the pores, which is also consistent with the results observed by XRD. A heterogeneous catalysis process often requires catalysts with large specific surface areas and better pore structures to provide more catalytic sites and facilitate molecular diffusion.

As shown in Figure 3, mesoporous silica has a diameter of about $400 \mathrm{~nm}$ and the ordered pore structure runs through the entire microsphere (Figure S1). Furthermore, the energydispersive X-ray spectroscopy (EDX) mapping (Figure 3d,h) shows that zirconium and magnesium are distributed on the mesoporous silica microspheres uniformly. Argon isothermal 


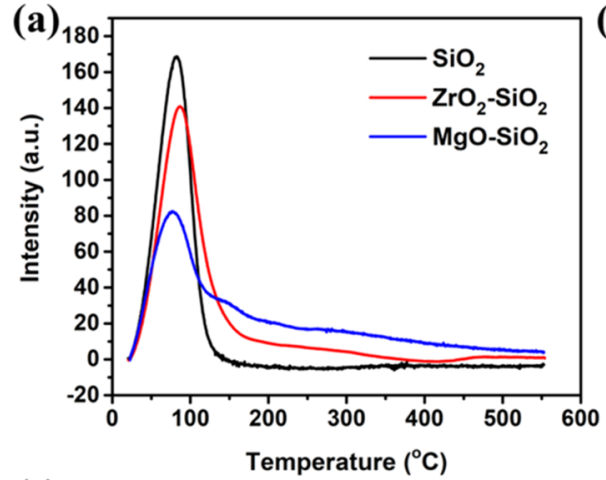

(c)

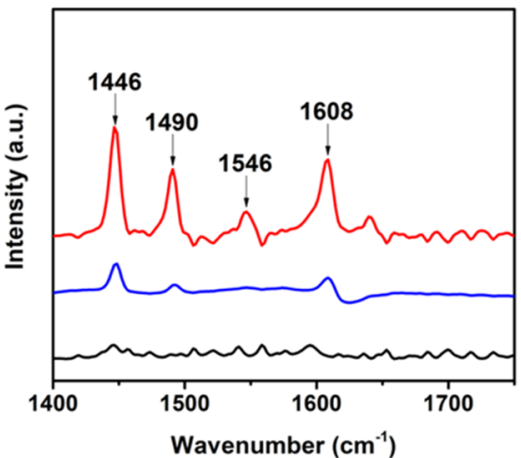

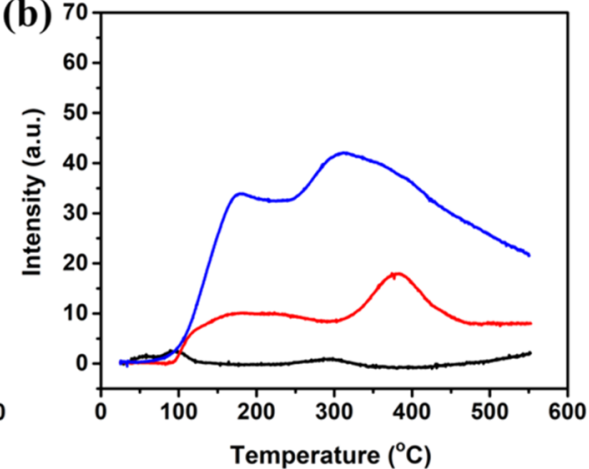

(d)<smiles></smiles>

Lewis acid

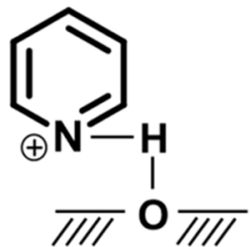

Bronsted acid

Figure 6. (a) $\mathrm{NH}_{3}$-TPD patterns and (b) $\mathrm{CO}_{2}$-TPD patterns of mesoporous silica materials, (c) Py-IR spectra of mesoporous silica materials, and (d) type of acid when pyridine is bonded to different atoms ( $\mathrm{M}$ : metal atom; $\mathrm{H}$ : hydrogen atom).

adsorption was used to determine the change in pore parameters of the mesoporous materials before and after loading the metal oxides.

As shown in Figure 4 and Table S2, the specific surface area and pore volume of all mesoporous-material-supported metal oxides decreased, but they still maintained a specific surface area of $200-1000 \mathrm{~m}^{2} \mathrm{~g}^{-1}$. This is larger than the surface area of many porous materials. The pore diameter and pore volume of $\mathrm{ZrO}_{2}-\mathrm{SiO}_{2}$ are slightly reduced, which are $2.96 \mathrm{~nm}$ and 0.54 $\mathrm{cm}^{3} \mathrm{~g}^{-1}$, respectively. This is due to the deposition of zirconia in the pores. The pore volume of $\mathrm{MgO}-\mathrm{SiO}_{2}$ decreased by $65 \%$. However, the pore diameter of $\mathrm{MgO}-\mathrm{SiO}_{2}$ increased slightly, reaching $3.19 \mathrm{~nm}$. This may be due to the strong basicity of $\mathrm{MgO}$ that reacts with $\mathrm{SiO}_{2}$ to cause the pores to be partially etched. The above results are consistent with the results of XRD observations. Inductively coupled plasma (ICP) (Table S1) results show that mass fractions of $\mathrm{Zr}$ and $\mathrm{Mg}$ in $\mathrm{ZrO}_{2}-\mathrm{SiO}_{2}$ and $\mathrm{MgO}-\mathrm{SiO}_{2}$ are 1.64 and $4.37 \%$, respectively. The results indicated that $\mathrm{SiO}_{2}$ is the central oxide as a carrier after compounding with other metal oxides.

X-ray photoelectron spectroscopy (XPS) was used to explore the valencies and types of the elements in the mesoporous catalysts. According to Figure 5, the binding energy of the $1 \mathrm{~s}$ peak of $\mathrm{Mg}$ is $1305 \mathrm{eV}$ and the binding energies of $3 \mathrm{~d}$ peaks of $\mathrm{Zr}$ are 183 and $186 \mathrm{eV}$, which indicated that both zirconium oxide and magnesium oxide could be loaded onto the silicon oxide surface by the impregnation process. According to Table S3, the $\mathrm{O} 1 \mathrm{~s}$ electron binding energy in $\mathrm{MgO}-\mathrm{SiO}_{2}$ is lower than that in $\mathrm{ZrO}_{2}-\mathrm{SiO}_{2}$ and $\mathrm{SiO}_{2}$, which means that the alkalinity of the oxygen anion is enhanced. Magnesium oxide is an alkaline-earth-metal oxide and an ideal solid base so that the composite exhibits alkalinity predominantly after being loaded onto silica. According to the report of Noller et al., ${ }^{39}$ the basic strength of $\mathrm{MgO}-\mathrm{SiO}_{2}$ is between that of $\mathrm{SiO}_{2}$ and $\mathrm{MgO}$; XPS results further validate the above inference.

Chemisorption determines the acid-base amount of the composite oxide. The temperature programmed desorption (TPD) experiments of $\mathrm{NH}_{3}$ (Figure 6a) show that after loading metal oxides the acid site amounts in $\mathrm{ZrO}_{2}-\mathrm{SiO}_{2}$ and $\mathrm{MgO}-\mathrm{SiO}_{2}$ are more than those in pure mesoporous silica, which are 1.50 and $1.26 \mathrm{mmol} \mathrm{g}^{-1}$, respectively. According to Tanabe's rule regarding the acidity of the metal complex oxide, ${ }^{40}$ the number of acid sites of $\mathrm{ZrO}_{2}-\mathrm{SiO}_{2}$ and $\mathrm{MgO}-$ $\mathrm{SiO}_{2}$ should be more than that of $\mathrm{SiO}_{2}$. The chemisorption results in Figure $6 a$ and Table 1 well fit this rule. The TPD

Table 1. Active Site Amounts of Different Mesoporous Silica Materials

\begin{tabular}{lcc}
\multicolumn{1}{c}{ material } & acid site amount $\left(\mathrm{mmol} \mathrm{g}^{-1}\right)$ & basic site amount $\left(\mathrm{mmol} \mathrm{g}^{-1}\right)$ \\
$\mathrm{SiO}_{2}$ & 0.86 & 0.51 \\
$\mathrm{ZrO}_{2}-\mathrm{SiO}_{2}$ & 1.50 & 10.02 \\
$\mathrm{MgO}-\mathrm{SiO}_{2}$ & 1.26 & 49.67 \\
\hline
\end{tabular}

experiments of $\mathrm{CO}_{2}$ (Figure 6b) show that the most basic adsorption site is in $\mathrm{MgO}-\mathrm{SiO}_{2}$, consistent with the strong alkaline property of $\mathrm{MgO}$. The pyridine in situ infrared adsorption spectra are further used to study the type of acids in different mesoporous silica materials.

As shown in Figure 6c, the peaks at 1446 and $1608 \mathrm{~cm}^{-1}$ indicate the adsorption of pyridine on the Lewis acid sites. The peak at $1546 \mathrm{~cm}^{-1}$ is ascribed to the Brønsted acid sites. The band at $1490 \mathrm{~cm}^{-1}$ is assigned to the simultaneous adsorption of pyridine on both Brønsted and Lewis acid sites. The peak area is directly proportional to the number of acid sites. The figure shows that $\mathrm{ZrO}_{2}-\mathrm{SiO}_{2}$ contains numerous Lewis acid sites and a few Brønsted acid sites. However, there is almost no Brønsted acid site in $\mathrm{MgO}-\mathrm{SiO}_{2}$ and $\mathrm{SiO}_{2}$. This indicates that 

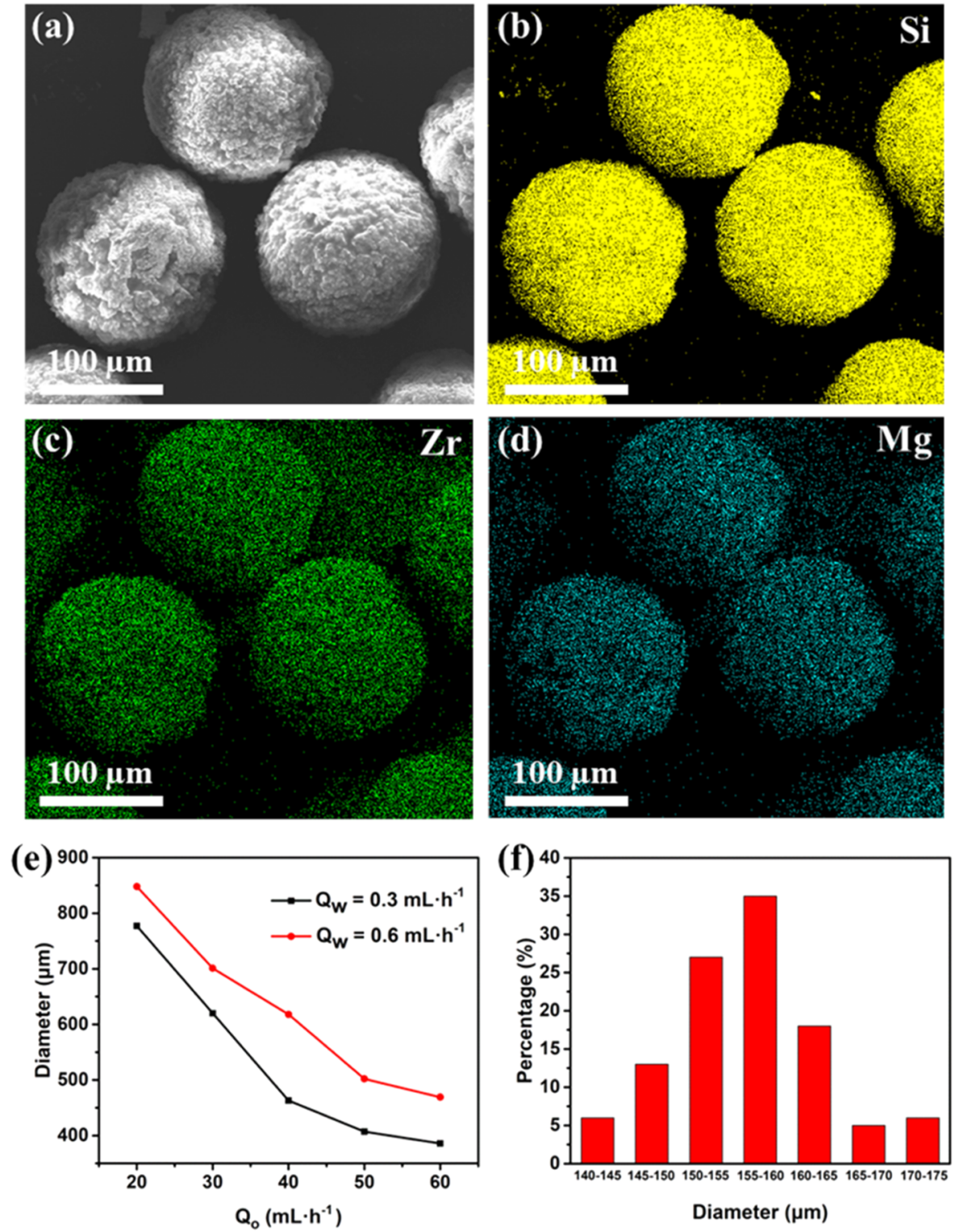

Figure 7. SEM images (a) and elemental mapping images of the multimodule composite microspheres; (b-d) distribution of Si, $\mathrm{Zr}$, and $\mathrm{Mg}$ in microspheres, respectively; (e) effect of dispersed phase flow rate $\left(Q_{w}\right)$ and continuous phase flow rate $\left(Q_{0}\right)$ on the size of the microdroplets; and (f) distribution of diameters of the dried microspheres.

the acidity of the surface hydroxyl groups of $\mathrm{MgO}-\mathrm{SiO}_{2}$ and $\mathrm{SiO}_{2}$ is not strong enough to convert pyridine into pyridine cation (Figure $6 \mathrm{~d}$ ). $\mathrm{ZrO}_{2}-\mathrm{SiO}_{2}$ porous materials have the most acidic sites in these three materials, which is in accordance with the results of the chemisorption.

Both catalytic units can be assembled into bifunctional catalytic microspheres in microfluidic chips. An aqueous solution containing $\mathrm{ZrO}_{2}-\mathrm{SiO}_{2}, \mathrm{MgO}-\mathrm{SiO}_{2}$, and sodium alginate was used as the dispersed phase, whereas liquid paraffin containing calcium chloride was used as the continuous phase. The microfluidic chip is constructed by combining a capillary with a cone and a three-dimensional (3D) printing part with a square channel (Figure S2). Compared with the conventional capillary flow focusing a microfluidic chip or $3 \mathrm{D}$ printing chip, this structure solves two problems. One is that the accuracy of an ordinary $3 \mathrm{D}$ printer is not enough, so it is difficult to accurately manufacture a needle tip with a diameter of $100 \mu \mathrm{m}$ or less. The other issue is that no expensive square capillary tube is used, which is replaced by the standard 3D printed project. At the same time, the operation of fabricating the microfluidic chip is significantly simplified. Tubes and chips can be combined with commercially available connectors. All of these have reduced the difficulty in the fabrication of microfluidic chips and improved the operability and repeatability of the experimental process. The liquid paraffin cuts the dispersed phase fluid into microdroplets, followed by the crosslinking of microdroplets by calcium chloride. As shown in Figure $7 \mathrm{a}$, the diameter of the dried microspheres was about $150 \mu \mathrm{m}$ and elemental mapping images (Figure $7 \mathrm{~b}-\mathrm{d}$ ) indicated that $\mathrm{Si}, \mathrm{Zr}$, and $\mathrm{Mg}$ were distributed in microspheres homogeneously.

As shown in Figure 7e, the diameter of the microdroplet can be conveniently controlled by adjusting the flow rate of the two-phase fluid. The obtained microdroplets have a smaller diameter when the flow rate of the dispersed phase is low, which is favorable for the diffusion of the reactants in the 

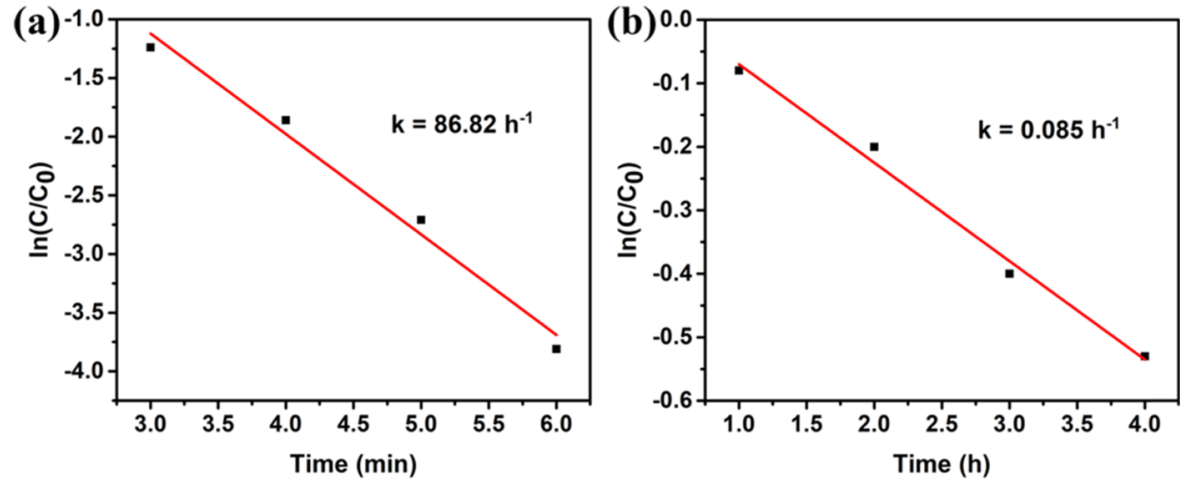

Figure 8. Results simulated by the first-order kinetic model: (a) deacetalization reaction and (b) Knoevenagel reaction.
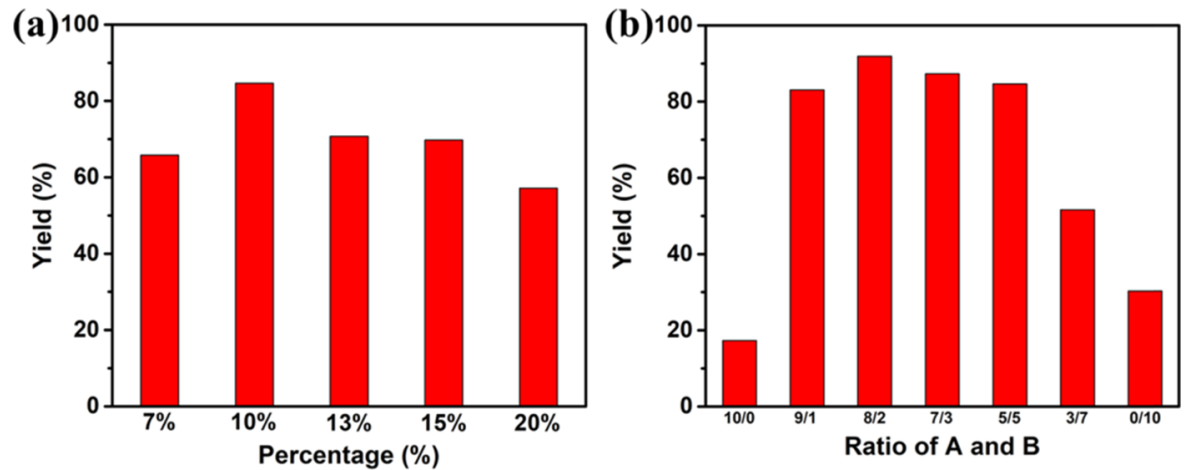

Figure 9. Catalytic performances of multimodule microspheres with different solid contents (a) and the different mass ratios of catalytic modules (b) in "one-pot" deacetalization-Knoevenagel condensation reactions $\left(\mathrm{A}: \mathrm{ZrO}_{2}-\mathrm{SiO}_{2} ; \mathrm{B}: \mathrm{MgO}-\mathrm{SiO}_{2}\right)$.

catalyst during the catalytic process. However, if the flow rate is too slow, the yield of the assembled microdroplets is low, so the flow rates of the disperse phase and the continuous phase are selected as 1.5 and $80 \mathrm{~mL} \mathrm{~h}^{-1}$, respectively.

The microspheres undergo subsequent heat treatment so that the cross-linked sodium alginate partially dehydrates and carbonizes to expose more pores and promote material transportation. The coefficient of variation of the assembled microspheres' diameter (Figure $7 \mathrm{f}$ ) was $4.7 \%$. The specific surface area and pore volume of the assembled multimodules microspheres were $439.51 \mathrm{~m}^{2} \mathrm{~g}^{-1}$ and $0.42 \mathrm{~cm}^{3} \mathrm{~g}^{-1}$, respectively (Figure 4 and Table S2).

Two composite oxide mesoporous nanoparticles were used to catalyze deacetalization and Knoevenagel reactions to investigate their acid and base catalytic properties, respectively. From the curve of conversion rate versus time, the deacetalization and Knoevenagel reactions catalyzed by the acid and base are both first-order reactions (Figure 8). The reaction rate coefficients are 86.82 and $0.085 \mathrm{~h}^{-1}$, respectively. The turnover frequency (TOF) values of $\mathrm{ZrO}_{2}-\mathrm{SiO}_{2}$ and $\mathrm{MgO}-\mathrm{SiO}_{2}$ catalysts are 1076.6 and $1.76 \mathrm{~h}^{-1}$, respectively. From the rate coefficients and TOF values, it can be seen that the deacetalization reaction proceeds faster than the Knoevenagel reaction.

The catalytic activity of bifunctional microspheres was investigated by the deacetalization-Knoevenagel cascade reaction. First, the content of complex oxides in the microspheres was explored (Figure 9a).

Keeping the same mass ratio of $\mathrm{ZrO}_{2}-\mathrm{SiO}_{2}$ and $\mathrm{MgO}-\mathrm{SiO}_{2}$ microspheres, changing the solid content in the dispersed phase can significantly change the catalytic efficiency. When the content of the solid catalyst in the dispersed phase is $10 \%$, its efficiency is the highest. The conversion of reactant benzaldehyde dimethyl acetal can reach $99 \%$, and the yield of the final product reaches $84 \%$ (Table 2). If the solid content

Table 2. Microspheres with Different Solid Contents Were Used as Catalysts for the Cascade Reaction

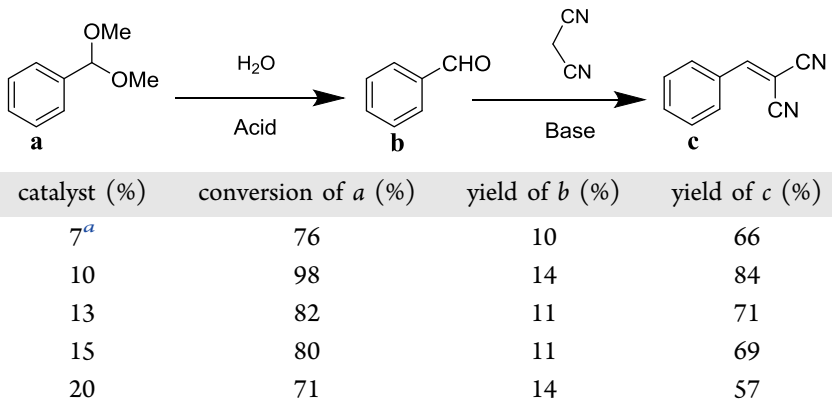

${ }^{a}$ Solid content of microspheres; the mass ratio of $\mathrm{ZrO}_{2}-\mathrm{SiO}_{2}$ and $\mathrm{MgO}-\mathrm{SiO}_{2}$ microspheres was 1:1.

is too high or too low, the conversion of the reactants will be reduced. This is because the higher the solid content in the dispersed phase, the higher the density of the resulting microspheres and thus the smaller the number of microspheres per mass catalyst. This is not conducive to the sufficient contact between the reactants and the catalyst in the heterogeneous reaction when the number of microspheres is small; thus, the catalytic efficiency is reduced. When the solid content in the dispersed phase is too small, although the number of microspheres per unit mass of the catalyst is significant, every single microsphere has little catalytically active substances, which is also not conducive to the catalytic 
reaction. Therefore, $10 \%$ of solids in the dispersed phase is the optimal content.

Due to the atomic percentages of $\mathrm{Zr}$ and $\mathrm{Mg}$ in the same mass composite oxides of the two catalysts is different. At the same time, the rates of the two reactions are also different (Figure 9b). Therefore, the proportion of $\mathrm{ZrO}_{2}-\mathrm{SiO}_{2}$ and $\mathrm{MgO}-\mathrm{SiO}_{2}$ in the bifunctional microspheres will also influence their catalytic activity.

Table 3 shows that when the microspheres contain only $\mathrm{ZrO}_{2}-\mathrm{SiO}_{2}$ the first-step reaction can be performed well with

Table 3. Microspheres with Different Ratios of $\mathrm{ZrO}_{2}-\mathrm{SiO}_{2}$ and $\mathrm{MgO}-\mathrm{SiO}_{2}$ Were Used as Catalysts for the Cascade

Reaction

\begin{tabular}{lccc}
\multicolumn{1}{c}{ catalyst } & conversion of $a(\%)$ & yield of $b(\%)$ & yield of $c(\%)$ \\
$10 \%^{a}-10: 0^{b}$ & 99 & 82 & 17 \\
$10 \%-9: 1$ & 94 & 11 & 83 \\
$10 \%-8: 2$ & 99 & 7 & 92 \\
$10 \%-7: 3$ & 95 & 7 & 87 \\
$10 \%-5: 5$ & 98 & 14 & 84 \\
$10 \%-3: 7$ & 80 & 28 & 52 \\
$10 \%-0: 10$ & 41 & 11 & 30
\end{tabular}

${ }^{a}$ Solid content of microspheres. ${ }^{b}$ Ratio of $\mathrm{ZrO}_{2}-\mathrm{SiO}_{2}$ and $\mathrm{MgO}-$ $\mathrm{SiO}_{2}$.

an acetal conversion rate of $99 \%$, but only $17 \%$ of the final product is formed because of the lack of a base. However, when only $\mathrm{MgO}-\mathrm{SiO}_{2}$ is contained, the conversion rate of acetal is not high, only $41 \%$, because there are fewer acid sites. However, since it can catalyze the Knoevenagel reaction as a solid base, the yield of the final product is $30 \%$. In the microspheres, the optimal ratio of the two catalytic components is $8: 2$. At this point, the acetal conversion is $99 \%$ and the final product yields $92 \%$. At this ratio, the atomic ratio of $\mathrm{Zr}$ and $\mathrm{Mg}$ in the microspheres is close to $1: 2.5$.

From the above results, we can see that even if the rate constant of the Knoevenagel reaction is far less than that of deacetalization the presence of a small amount of $\mathrm{MgO}$ can still make the second-step reaction of cascade reaction proceed efficiently. The rate constants of the two reactions have a difference of 1021 times. The second reaction, Knoevenagel reaction, is the rate-determining step in the cascade reaction. However, the residual amount of intermediate products (benzaldehyde) in the cascade reaction was always at a low level (Figure 10) when the microspheres were used as a catalyst. This may be due to the fact that the distance between acidic catalytic centers and alkaline centers is very short because of assembling and the intermediate products produced at the acid center can rapidly contact the basic active center, thereby converting into the final product.

Control experiments show that pure sodium alginate microspheres can hardly produce a catalytic effect on the reaction (Table 4). Therefore, the use of sodium alginate as a cross-linking agent does not affect the catalytic results. Also, when mesoporous $\mathrm{SiO}_{2}$ alone is used as a catalyst, since $\mathrm{SiO}_{2}$ is both acidic and basic, it can partially catalyze the cascade reaction. However, its acidity and alkalinity are weak, so the conversion and yield of the reaction are quite low.

These dual-function microspheres assembled from simple modules can provide more functionality by continuing to add functional modules. For example, magnetic $\mathrm{Fe}_{3} \mathrm{O}_{4}$ particles were also compounded into microspheres by self-assembly to

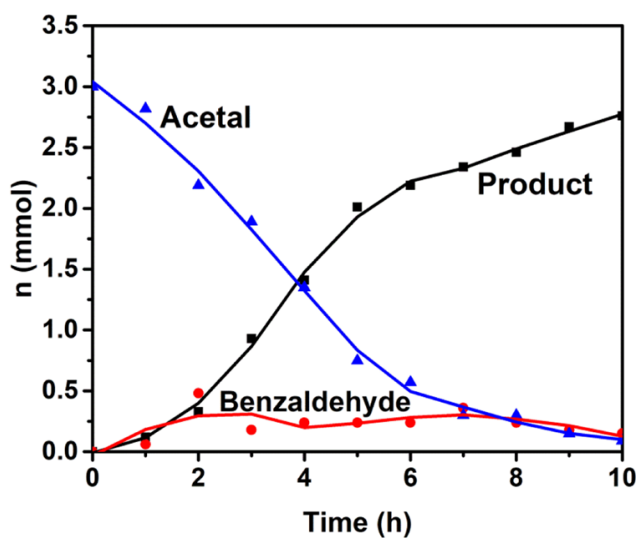

Figure 10. Evolution of the reactant (acetal, solid blue triangles), intermediate product (benzaldehyde, solid red circles), and the final product (benzylidene malononitrile, solid black squares) versus reaction time; microspheres of $10 \%-8: 2$ were used as catalysts.

Table 4. Blank Control Experiments and Experiments Exploring the Influence of Magnetic Particles

\begin{tabular}{lccc}
\multicolumn{1}{c}{ catalyst } & $\begin{array}{c}\text { conversion of } a \\
(\%)\end{array}$ & yield of $b(\%)$ & yield of $c(\%)$ \\
$1 \%^{a}$ sodium alginate & 5 & 1 & 4 \\
$10 \%^{b} \mathrm{SiO}_{2}$ & 51 & 22 & 29 \\
$10 \%-8: 2^{c}-1 \%^{d} \mathrm{Fe}_{3} \mathrm{O}_{4}$ & 96 & 4 & 92
\end{tabular}

${ }^{a}$ In the process of microfluidic assembly of microspheres, the dispersed phase was $1 \%$ sodium alginate solution. ${ }^{b}$ Solid content of microspheres. ${ }^{c}$ Ratios of $\mathrm{ZrO}_{2}-\mathrm{SiO}_{2}$ and $\mathrm{MgO}-\mathrm{SiO}_{2}$. ${ }^{d}$ Content of $\mathrm{Fe}_{3} \mathrm{O}_{4}$ in microspheres.

form trifunctional microspheres. The saturation susceptibility of composite microspheres is $7.2 \mathrm{emu} \mathrm{g}^{-1}$ (Figure 11a).

After the catalytic reaction is over, the catalyst can be conveniently removed by applying a magnetic field. At the same time, the conversion and final yield of the reactants can still reach 96 and 92\% (Table 4), respectively, which are similar to the results when a nonmagnetic bifunctional catalyst is used. The addition of the magnetic function does not have any adverse effect on the catalytic reaction. The functions among the modules are mutually orthogonal and do not interfere with each other. The results of the repeated use of the catalysts showed that after the fifth cycle (Figure 11b) the reaction yield did not reduce too much. After several reuse cycles, the color of catalysts changes from light yellow to yellowish brown, indicating that the macromolecular organics were deposited in the pores of catalysts. They will cover part of the active sites. However, there is no significant change in the surface of the microspheres (Figure 12). Also, the catalysts were partially pulverized during use, which will result in the loss of active ingredients.

\section{CONCLUSIONS}

In summary, in this work, nanoparticles with acid-base catalytic properties and magnetic properties were used as building blocks to fabricate the microsphere system with multifunctional integration. The microspheres show a high catalytic performance on the acid-base cascade reaction and can be removed by the external magnetic field. The preparation of solid elements is simple, but the function of the composite microspheres is complex. With the assembly process in the microdroplets, the diameter and composition of 

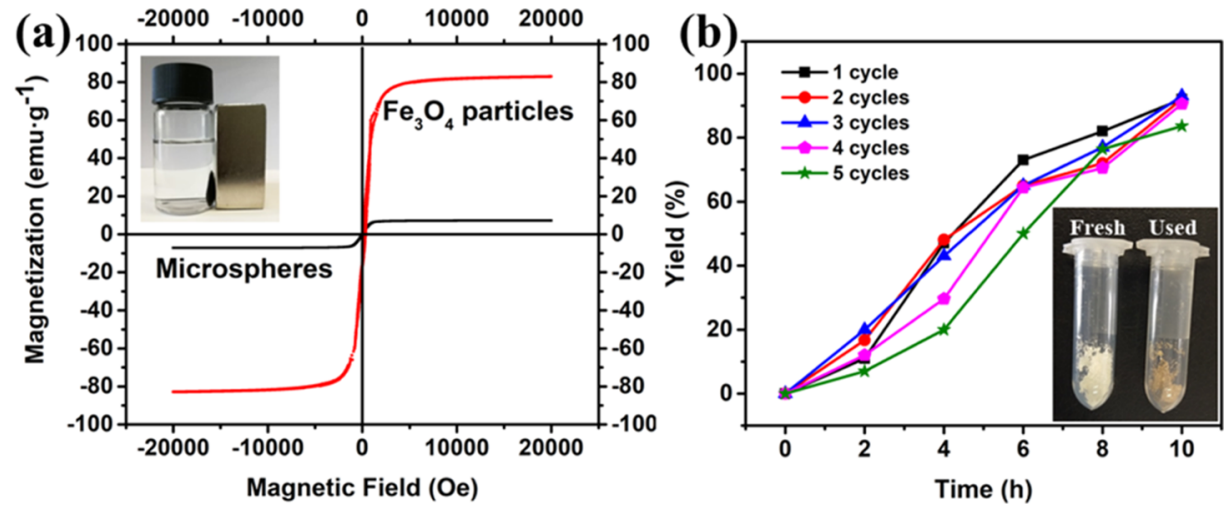

Figure 11. (a) Magnetization curves of $\mathrm{Fe}_{3} \mathrm{O}_{4}$ particles and multimodules microspheres at $300 \mathrm{~K}$ in the applied magnetic field ranging from -20 000 to $20000 \mathrm{Oe}$; the illustration was the magnetic separation process of microspheres. (b) Recycling tests of microspheres during the deacetalization-Knoevenagel cascade reaction; the illustration was a comparison of the catalysts before and after use.
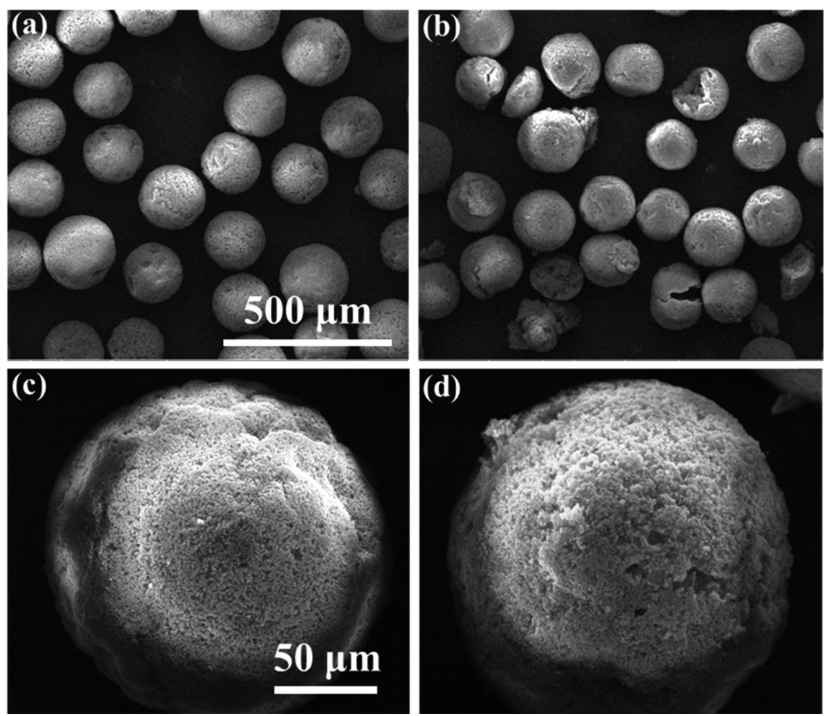

Figure 12. SEM images of the fresh catalysts $(a, c)$ and used catalysts $(b, d)$.

the microspheres can be quickly adjusted to achieve the precise control of the function. Using different mesoporous silica materials as catalysts, the catalytic process in the cascade catalytic reaction can be conveniently studied. As can be seen from above, this modular self-assembly preparation method fully reflects the enormous power of complexity resulting from simplicity. This method provides a useful reference and practical technical support for the design and fabrication of other multifunctional-integrated "All-in-One" materials.

\section{EXPERIMENTAL SECTION}

4.1. Reactants and Materials. Cetyltrimethylammonium bromide, tetraethyl orthosilicate, ammonia solution (25 wt \%), ethanol, toluene, 1-propanol were obtained from Beijing Chemical Reagents Company. Liquid paraffin, magnesium nitrate, sodium alginate, sodium acetate, ferric chloride, and calcium chloride were bought from Guangfu Fine Chemical of Tianjin Co. Ltd., Tianjin, P. R. China. Span 80, zirconium npropoxide $\left(\mathrm{Zr}(\mathrm{OPr})_{4}\right)$, benzaldehyde, malononitrile, and benzaldehyde dimethyl acetal were bought from Aladdin Chemical Co., Ltd. Ethyl alcohol and poly(ethylene glycol) were purchased from Fuyu Fine Chemical of Tianjin Co. Ltd.
4.2. Preparation of Modular Nanoparticles. 4.2.1. Preparation of Acidic Mesoporous Silica Particles. Mesoporous $\mathrm{SiO}_{2}$ was prepared by a modified method. ${ }^{41-47}$ In the preparation of $\mathrm{ZrO}_{2}-\mathrm{SiO}_{2}, 2 \mathrm{~g}$ of zirconium propoxide solution $\left(\mathrm{C}_{12} \mathrm{H}_{28} \mathrm{O}_{4} \mathrm{Zr}\right)$ was diluted with $150 \mathrm{~mL}$ of 1-propanol and then $1.5 \mathrm{~g}$ of mesoporous $\mathrm{SiO}_{2}$ was added to this solution. The mixture was further stirred for $24 \mathrm{~h}$ at room temperature. $^{48,49}$ The suspension was filtered, and the precipitate was washed with absolute ethanol. After being dried at $60{ }^{\circ} \mathrm{C}$, the product was calcined in a muffle furnace at $550{ }^{\circ} \mathrm{C}$ for $5 \mathrm{~h}$ in the presence of air.

4.2.2. Preparation of Basic Mesoporous Silica Particles. In the preparation of $\mathrm{MgO}-\mathrm{SiO}_{2}, 1.64 \mathrm{~g}$ of magnesium nitrate hexahydrate $\left(\mathrm{Mg}\left(\mathrm{NO}_{3}\right)_{2} \cdot 6 \mathrm{H}_{2} \mathrm{O}\right)$ was dissolved in $60 \mathrm{~mL}$ of ethanol and then $1.0 \mathrm{~g}$ of mesoporous $\mathrm{SiO}_{2}$ was added to this solution. ${ }^{50,51}$ The mixture was further stirred for $4 \mathrm{~h}$ followed by rotary evaporation at $45{ }^{\circ} \mathrm{C}$. The obtained powders were calcined in a muffle furnace at $550^{\circ} \mathrm{C}$ for $5 \mathrm{~h}$ in the presence of air.

4.2.3. Preparation of Magnetic $\mathrm{Fe}_{3} \mathrm{O}_{4}$ Particles. $\mathrm{FeCl}_{3}$. $6 \mathrm{H}_{2} \mathrm{O}(1.35 \mathrm{~g})$ was dissolved in ethylene glycol $(40 \mathrm{~mL})$ to form a clear solution, followed by the addition of $\mathrm{NaAc}(3.6 \mathrm{~g})$ and poly(ethylene glycol) (1.0 g). The mixture was stirred for $30 \mathrm{~min}$ and sealed in a Teflon-lined stainless steel autoclave. The autoclave was heated to and maintained at $200{ }^{\circ} \mathrm{C}$ for $8 \mathrm{~h}$ and then cooled to room temperature. ${ }^{52-56}$ The products were washed with ethanol several times and dried in vacuum at 60 ${ }^{\circ} \mathrm{C}$ for $12 \mathrm{~h}$.

4.3. Microfluidic Device. A microfluidic chip was fabricated by assembling a capillary glass tube with a 3D printed tube. Round borosilicate glass capillaries (Sutter Instrument Co.) with an inner diameter of $0.58 \mathrm{~mm}$ and an outer diameter of $1.00 \mathrm{~mm}$ were tapered to the desired diameters by applying a micropipette puller (P-1000, Sutter Instrument $\mathrm{Co}$.). The tapered glass capillaries were polished with sandpaper (CC88P, P3000, MT, Inc.) so that the inner capillary tip diameter was $150 \mu \mathrm{m}$. The outer tube was fabricated by a $3 \mathrm{D}$ printer (Formlabs, Form 2). The round capillary was inserted inside an outer tube and then glued in place (with epoxy resin, Devcon). Liquids were delivered to the microfluidic chip via two syringe pumps (Longer Pump, model LSP01-2A) with tubing (Figure S2).

4.4. Self-Assembly of Particles in a Microfluidic Chip. The self-assembly process used to produce the multimodule microspheres is illustrated in Scheme 1. Sodium alginate (1.0 
Scheme 1. Schematic Illustration of the Fabrication Process and Application of the Multimodule Microspheres

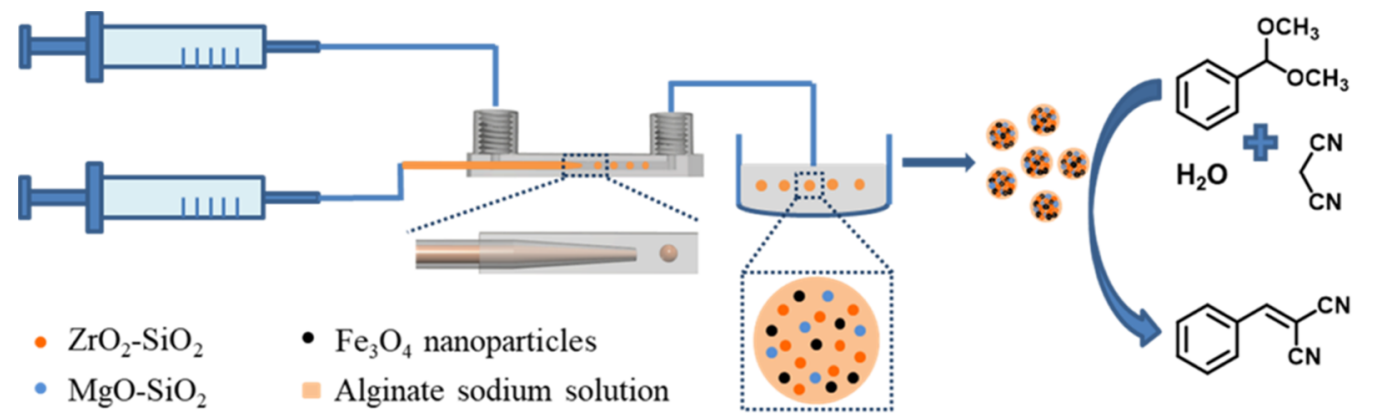

g) was added to deionized water to prepare $1.0 \mathrm{wt} \%$ of sodium alginate aqueous solution. Nanoparticles were dispersed in the prepared sodium alginate aqueous solution to obtain a uniform liquid mixture, which was used as the inner phase. The outer phase was liquid paraffin containing 3 wt $\%$ of Span 80 . The solidification bath was liquid paraffin containing 3 wt \% of Span 80 and 2 wt $\%$ of $\mathrm{CaCl}_{2}$. The inner phase was injected into the microchannel and separated into monodispersed droplets under the shearing force of the outer phase. Droplets were collected in solidification bath for further cross-linking and then the microspheres were washed thoroughly with light petroleum and ethanol. The microspheres were dried at $60{ }^{\circ} \mathrm{C}$ and then heated to $200{ }^{\circ} \mathrm{C}$ for $2 \mathrm{~h}$.

4.5. Catalytic Property of Prepared Hybrid Catalysts. The catalytic performance of different hybrid microsphere catalysts was evaluated by several reactions.

4.5.1. Deacetalization Reaction. In a typical procedure, a mixture of benzaldehyde dimethyl acetal $(2 \mathrm{mmol})$, deionized water $(0.15 \mathrm{~mL})$, and $\mathrm{ZrO}_{2}-\mathrm{SiO}_{2}(0.1 \mathrm{~g})$ in toluene $(4 \mathrm{~mL})$ was kept at $80{ }^{\circ} \mathrm{C}$ under mechanical stirring. The sample mixture was removed with a pipette and evaluated by gas chromatography (GC) to determine the yield.

4.5.2. Knoevenagel Reaction. A mixture of benzaldehyde $(2 \mathrm{mmol})$, malononitrile $(6 \mathrm{mmol})$, and $\mathrm{MgO}-\mathrm{SiO}_{2}(0.1 \mathrm{~g})$ in toluene $(4 \mathrm{~mL})$ was kept at $80{ }^{\circ} \mathrm{C}$ under mechanical stirring. The sample mixture was removed with a pipette and evaluated by GC to determine the yield.

4.5.3. One-Pot Deacetalization-Knoevenagel Cascade Reaction. A mixture of benzaldehyde dimethyl acetal (3 $\mathrm{mmol})$, deionized water $(0.15 \mathrm{~mL})$, malononitrile $(6 \mathrm{mmol})$, and assembled microspheres $(0.15 \mathrm{~g})$ in toluene $(9 \mathrm{~mL})$ was kept at $80{ }^{\circ} \mathrm{C}$ for $10 \mathrm{~h}$ under mechanical stirring. The sample mixture was removed with a pipette and evaluated by GC to determine the yield. The final product was analyzed by mass spectrography (Figure S3).

4.6. Characterization. X-ray diffraction (XRD) patterns of the prepared mesoporous silica particles were obtained at room temperature on a Rigaku D/MAX-2400 X-ray powder diffractor (Japan) using $\mathrm{Cu} \mathrm{K} \alpha$ radiation, operating at $40 \mathrm{kV}$ and $10 \mathrm{~mA}$. The argon adsorption and desorption isotherms were measured at $87 \mathrm{~K}$ using a $3 \mathrm{H}-2000 \mathrm{PSI}$ analyzer. Surface areas were calculated by the Brunauer-Emmett-Teller method, and the pore volume and pore size distributions were calculated using the density functional theory model. ${ }^{57,58}$ The scanning electron microscopy (SEM) images were taken with a JEOL JSM-6700F field-emission scanning electron microscope (FE-SEM). The mesoporous structures of silica materials were observed by an FEI TITAN 80-300 transmission electron microscope (TEM). Magnetic character- ization was carried out using a VSM with fields up to 20000 $\mathrm{Oe}$ and at a temperature of $300 \mathrm{~K}$. Related ion concentration was collected on a PerkinElmer Optima 2000DV inductively coupled plasma (ICP) spectroscopy. An ESCALAB250 X-ray photoelectric spectrometer (Thermo VG Scientific) was used to analyze the composition of elements on the nanoparticles. Droplets and microspheres were first observed with a Phantom camera (MIRO C210, York Technologies Ltd.). Temperatureprogrammed desorption of ammonia/carbon dioxide $\left(\mathrm{NH}_{3} /\right.$ $\mathrm{CO}_{2}$-TPD) was performed on Builder PCA-1200. Concentrations of reactants and products were determined by a gas chromatograph (GC7900, TECHCOMP).

\section{ASSOCIATED CONTENT}

\section{Supporting Information}

The Supporting Information is available free of charge on the ACS Publications website at DOI: 10.1021/acsomega.8b03098.

TEM images of mesoporous silica materials; process of assembling microfluidic chip and producing microspheres by the microfluidic device; mass spectrogram of the final product of cascade reaction; the mass fraction of $\mathrm{Zr}$ and $\mathrm{Mg}$ in $\mathrm{ZrO}_{2}-\mathrm{SiO}_{2}$ and $\mathrm{MgO}-\mathrm{SiO}_{2}$, respectively; physical parameters of different mesoporous silica materials and the multimodule microspheres; $\mathrm{O} 1 \mathrm{~s}$ peak position of different mesoporous silica materials (PDF)

\section{AUTHOR INFORMATION}

\section{Corresponding Author}

*E-mail: taosy@dlut.edu.cn.

ORCID 웅

Shengyang Tao: 0000-0002-0567-8860

Guangtao Li: 0000-0003-4127-1715

Xin Liu: 0000-0002-4422-4108

Notes

The authors declare no competing financial interest.

\section{ACKNOWLEDGMENTS}

The authors are grateful to the National Natural Science Foundation of China (21473019 and 51703017), the financial grant from the China Postdoctoral Science Foundation (2016M601302), and the Fundamental Research Funds for the Central Universities (DUT 17LK36) for their financial support. 


\section{REFERENCES}

(1) Lee, L. C.; Lu, J.; Weck, M.; Jones, C. W. Acid-Base Bifunctional Shell Cross-Linked Micelle Nanoreactor for One-Pot Tandem Reaction. ACS Catal. 2016, 6, 784-787.

(2) Climent, M. J.; Corma, A.; Iborra, S.; Santos, L. L. Multisite Solid Catalyst for Cascade Reactions: the Direct Synthesis of Benzodiazepines from Nitro Compounds. Chem. - Eur. J. 2009, 15, 8834-8841.

(3) Görbe, T.; Gustafson, K. P. J.; Verho, O.; Kervefors, G.; Zheng, H.; Zou, X.; Johnston, E. V.; Bäckvall, J. E. Design of a Pd(0)-CalB CLEA Biohybrid Catalyst and Its Application in a One-Pot Cascade Reaction. ACS Catal. 2017, 7, 1601-1605.

(4) An, Z.; Guo, Y.; Zhao, L.; Li, Z.; He, J. 1-Proline-Grafted Mesoporous Silica with Alternating Hydrophobic and Hydrophilic Blocks to Promote Direct Asymmetric Aldol and KnoevenagelMichael Cascade Reactions. ACS Catal. 2014, 4, 2566-2576.

(5) Leng, W.; Peng, Y.; Zhang, J.; Lu, H.; Feng, X.; Ge, R.; Gao, Y.; et al. Sophisticated Design of Covalent Organic Frameworks with Controllable Bimetallic Docking for a Cascade Reaction. Chem. - Eur. J. 2016, 22, 9087-9091.

(6) Gao, J.; Zhang, X.; Lu, Y.; Liu, S.; Liu, J. Selective Functionalization of Hollow Nanospheres with Acid and Base Groups for Cascade Reactions. Chem. - Eur. J. 2015, 21, 7403-7407.

(7) Abdelrahman, O. A.; Park, D. S.; Vinter, K. P.; Spanjers, C. S.; Ren, L.; Cho, H. J.; Zhang, K.; Fan, W.; Tsapatsis, M.; Dauenhauer, P. $\mathrm{J}$. Renewable Isoprene by Sequential Hydrogenation of Itaconic Acid and Dehydra-Decyclization of 3-Methyl-Tetrahydrofuran. ACS Catal. 2017, 7, 1428-1431.

(8) Baylon, R. A. L.; Sun, J.; Kovarik, L.; Engelhard, M.; Li, H.; Winkelman, A. D.; Wang, Y. Structural Identification of $\mathrm{Zn}_{\mathrm{x}} \mathrm{Zr}_{\mathrm{y}} \mathrm{O}_{\mathrm{z}}$ Catalysts for Cascade Aldolization and Self-Deoxygenation Reactions. Appl. Catal., B 2018, 234, 337-346.

(9) Li, H.; Pan, Q.; Ma, Y.; Guan, X.; Xue, M.; Fang, Q.; Yan, Y.; Valtchev, V.; Qiu, S. Three-Dimensional Covalent Organic Frameworks with Dual Linkages for Bifunctional Cascade Catalysis. J. Am. Chem. Soc. 2016, 138, 14783-14788.

(10) Wang, X.; Guan, B.; He, Y.; Zhang, Y.; Cao, Y.; Liu, Y.; Qiao, Z. A.; Huo, Q. Synthesis of Janus Mesoporous Silica Nanostructures with Organic-Inorganic Hybrid Components through a Sprout-Like Growth Method. ChemNanoMat 2015, 1, 562-566.

(11) Shao, Y.; Guan, J.; Wu, S.; Liu, H.; Liu, B.; Kan, Q. Synthesis, Characterization and Catalytic Activity of Acid-Base Bifunctional Materials by Controlling Steric Hindrance. Microporous Mesoporous Mater. 2010, 128, 120-125.

(12) Wang, F.; Wang, G.; Sun, W.; Wang, T.; Chen, X. Metallophthalocyanine Functionalized Magnetic Mesoporous Silica Nanoparticles and Its Application in Ultrasound-Assisted Oxidation of Benzothiophene. Microporous Mesoporous Mater. 2015, 217, 203-209.

(13) Shang, F.; Sun, J.; Wu, S.; Yang, Y.; Kan, Q.; Guan, J. Direct Synthesis of Acid-Base Bifunctional Mesoporous MCM-41 Silica and Its Catalytic Reactivity in Deacetalization-Knoevenagel Reactions. Microporous Mesoporous Mater. 2010, 134, 44-50.

(14) Lin, Q.; Chen, Y.; Tang, Y.; Wu, K.; Yang, M.; Hu, H.; Wu, Y. Catalytic Hydrothermal Liquefaction of D. tertiolecta over Multifunctional Mesoporous Silica-Based Catalysts with High Stability. Microporous Mesoporous Mater. 2017, 250, 120-127.

(15) Yang, Y.; Yao, H. F.; Xi, F. G.; Gao, E. Q. AminoFunctionalized $\mathrm{Zr}(\mathrm{IV})$ Metal-Organic Framework as Bifunctional Acid-Base Catalyst for Knoevenagel Condensation. J. Mol. Catal. A: Chem. 2014, 390, 198-205.

(16) Weng, B.; Lu, K. Q.; Tang, Z.; Chen, H. M.; Xu, Y. J. Stabilizing Ultrasmall $\mathrm{Au}$ Clusters for Enhanced Photoredox Catalysis. Nat. Commun. 2018, 9, No. 1543.

(17) Postole, G.; Chowdhury, B.; Karmakar, B.; Pinki, K.; Banerji, J.; Auroux, A. Knoevenagel Condensation Reaction over Acid-Base Bifunctional Nanocrystalline $\mathrm{Ce}_{\mathrm{x}} \mathrm{Zr}_{1-\mathrm{x}} \mathrm{O}_{2}$ Solid Solutions. J. Catal. 2010, 269, 110-121.

(18) He, H.; Sun, F.; Aguila, B.; Perman, J. A.; Ma, S.; Zhu, G. A Bifunctional Metal-Organic Framework Featuring the Combination of
Open Metal Sites and Lewis Basic Sites for Selective Gas Adsorption and Heterogeneous Cascade Catalysis. J. Mater. Chem. A 2016, 4, $15240-15246$.

(19) Song, T. Y.; Dong, Z. X.; Song, J. D.; Wang, X. X.; Xie, G. Q.; Luo, M. F.; Lu, J. Q. Dehydrochlorination of 1, 1, 2-Trichloroethane over $\mathrm{SiO}_{2}$-Supported Alkali and Transition Metal Catalysts: Tunable Selectivity Controlled by the Acid-Base Properties of the Catalysts. Appl. Catal., B 2018, 236, 368-376.

(20) Li, H.; Fang, Z.; Luo, J.; Yang, S. Direct Conversion of Biomass Components to the Biofuel Methyl Levulinate Catalyzed by Acid-Base Bifunctional Zirconia-Zeolites. Appl. Catal., B 2017, 200, 182-191.

(21) Gaona, A.; Díaz, U.; Corma, A. Functional Acid and Base Hybrid Catalysts Organized by Associated (Organo) Aluminosilicate Layers for C-C Bond Forming Reactions and Tandem Processes. Chem. Mater. 2017, 29, 1599-1612.

(22) Wang, D.; Wang, B.; Ding, Y.; Wu, H.; Wu, P. A Novel AcidBase Bifunctional Catalyst (ZSM-5@ $\mathrm{Mg}_{3} \mathrm{Si}_{4} \mathrm{O}_{9}(\mathrm{OH})_{4}$ ) with Core/ Shell Hierarchical Structure and Superior Activities in Tandem Reactions. Chem. Commun. 2016, 52, 12817-12820.

(23) Suttipat, D.; Wannapakdee, W.; Yutthalekha, T.; Ittisanronnachai, S.; Ungpittagul, T.; Phomphrai, K.; Bureekaew, S.; Wattanakit, C. Hierarchical FAU/ZIF-8 Hybrid Materials as Highly Efficient Acid-Base Catalysts for Aldol Condensation. ACS Appl. Mater. Interfaces 2018, 10, 16358-16366.

(24) Jia, Z.; Wang, K.; Tan, B.; Gu, Y. Hollow Hyper-Cross-Linked Nanospheres with Acid and Base Sites as Efficient and Water-Stable Catalysts for One-Pot Tandem Reactions. ACS Catal. 2017, 7, 36933702.

(25) Rathod, P. V.; Nale, S. D.; Jadhav, V. H. Metal Free Acid Base Catalyst in the Selective Synthesis of 2,5-Diformylfuran from Hydroxymethylfurfural, Fructose, and Glucose. ACS Sustainable Chem. Eng. 2017, 5, 701-707.

(26) Bodhak, C.; Kundu, A.; Pramanik, A. $\mathrm{ZrO}_{2}$ Nanoparticles as a Reusable Solid Dual Acid-Base Catalyst for Facile One-Pot Synthesis of Multi-Functionalized Spirooxindole Derivatives under Solvent-Free Condition. RSC Adv. 2015, 5, 85202-85213.

(27) Ge, T.; Hua, Z.; Zhu, Y.; Song, Y.; Tao, G.; Zhou, X.; Chen, L.; Ren, W.; Yao, H.; Shi, J. Amine-Modified Hierarchically Structured Zeolites as Acid-Base Bifunctional Catalysts for One-Pot Deacetalization-Knoevenagel Cascade Reaction. RSC Adv. 2014, 4, 6487164876.

(28) Wang, K.; Jia, Z.; Yang, X.; Wang, L.; Gu, Y.; Tan, B. Acid and Base Coexisted Heterogeneous Catalysts Supported on Hypercrosslinked Polymers for One-Pot Cascade Reactions. J. Catal. 2017, 348, 168-176.

(29) Aider, N.; Smuszkiewicz, A.; Pérez-Mayoral, E.; Soriano, E.; Martín-Aranda, R. M.; Halliche, D.; Menad, S. Amino-Grafted SBA15 Material as Dual Acid-Base Catalyst for the Synthesis of Coumarin Derivatives. Catal. Today 2014, 227, 215-222.

(30) Weng, Z.; Yu, T.; Zaera, F. Synthesis of Solid Catalysts with Spatially Resolved Acidic and Basic Molecular Functionalities. ACS Catal. 2018, 8, 2870-2879.

(31) Wang, P.; Li, J.; Nunes, J.; Hao, S.; Liu, B.; Chen, H. Droplet Micro-Reactor for Internal Gelation to Fabricate $\mathrm{ZrO}_{2}$ Ceramic Microspheres. J. Am. Ceram. Soc. 2017, 100, 41-48.

(32) Cui, Q.; Zhao, H.; Luo, G.; Xu, J. An Efficient Chitosan/Silica Composite Core-Shell Microspheres-Supported Pd Catalyst for Aryl Iodides Sonogashira Coupling Reactions. Ind. Eng. Chem. Res. 2017, $56,143-152$.

(33) Costantini, M.; Guzowski, J.; Żuk, P. J.; Mozetic, P.; De Panfilis, S.; Jaroszewicz, J.; Heljak, M.; Massimi, M.; Pierron, M.; Trombetta, M.; Dentini, M.; Święszkowski, W.; Rainer, A.; Garstecki, P.; Barbetta, A. Electric Field Assisted Microfluidic Platform for Generation of Tailorable Porous Microbeads as Cell Carriers for Tissue Engineering. Adv. Funct. Mater. 2018, 28, No. 1800874.

(34) Han, T.; Zhang, L.; Xu, H.; Xuan, J. Factory-On-Chip: Modularised Microfluidic Reactors for Continuous Mass Production of Functional Materials. Chem. Eng. J. 2017, 326, 765-773. 
(35) Wang, J.; Li, J.; Wang, Y.; Luo, G. In Situ Preparation of Pd/ $\mathrm{Al}_{2} \mathrm{O}_{3}-\mathrm{SiO}_{2}$ Composite Microspheres by Combining a Sol-Gel Process and Precipitation Process in a Microchannel. Chem. Eng. J. 2014, 236, 293-299.

(36) Zhao, H.; Xu, J. H.; Wang, T.; Luo, G. S. A Novel Microfluidic Approach for Preparing Chitosan-Silica Core-Shell Hybrid Microspheres with Controlled Structures and Their Catalytic Performance. Lab Chip 2014, 14, 1901-1906.

(37) Zhao, H.; Xu, J.; Wang, T. Silica/Chitosan Core-Shell HybridMicrosphere-Supported CuI Catalyst for Terminal Alkyne Homocoupling Reaction. Appl. Catal., A 2015, 502, 188-194.

(38) Sun, L.; Wang, J.; Yu, Y.; Bian, F.; Zou, M.; Zhao, Y. Graphene Oxide Hydrogel Particles from Microfluidics for Oil Decontamination. J. Colloid Interface Sci. 2018, 528, 372-378.

(39) Noller, H.; Lercher, J. A.; Vinek, H. Acidic and Basic Sites of Maim Group Mixed Metal Oxides. Mater. Chem. Phys. 1988, 18, 577593.

(40) Tanabe, K.; Misono, M.; Hattori, H.; Ono, Y. New Solid Acids and Bases: Their Catalytic Properties; Elsevier, 1990; Vol. 51, pp 1364.

(41) Yang, P.; Gai, S.; Lin, J. Functionalized Mesoporous Silica Materials for Controlled Drug Delivery. Chem. Soc. Rev. 2012, 41, 3679-3698.

(42) Ding, B. J.; Wang, J.; Tao, S. Y.; Ding, Y. Z.; Zhang, L. J.; Gao, N.; Ge, S.; et al. Fabrication of Multi-Functional Porous Microspheres in A Modular Fashion for the Detection, Adsorption, and Removal of Pollutants in Wastewater. J. Colloid Interface Sci. 2018, 522, 1-9.

(43) Shi, Y.; Zhang, F.; Hu, Y. S.; Sun, X.; Zhang, Y.; Lee, H. I.; Chen, L.; Stucky, G. D. Low-Temperature Pseudomorphic Transformation of Ordered Hierarchical Macro-Mesoporous $\mathrm{SiO}_{2} / \mathrm{C}$ Nanocomposite to $\mathrm{SiC}$ via Magnesiothermic Reduction. J. Am. Chem. Soc. 2010, 132, 5552-5553.

(44) Yamada, H.; Urata, C.; Aoyama, Y.; Osada, S.; Yamauchi, Y.; Kuroda, K. Preparation of Colloidal Mesoporous Silica Nanoparticles with Different Diameters and Their Unique Degradation Behavior in Static Aqueous Systems. Chem. Mater. 2012, 24, 1462-1471.

(45) Heleg-Shabtai, V.; Aizen, R.; Sharon, E.; Sohn, Y. S.; Trifonov, A.; Enkin, N.; Willner, I.; et al. Gossypol-Capped MitoxantroneLoaded Mesoporous $\mathrm{SiO}_{2}$ NPs for the Cooperative Controlled Release of Two Anti-Cancer Drugs. ACS Appl. Mater. Interfaces 2016, 8, 14414-14422.

(46) Zhao, T.; Zhu, X.; Hung, C. T.; Wang, P.; Elzatahry, A.; AlKhalaf, A. A.; Zhao, D.; et al. Spatial Isolation of Carbon and Silica in a Single Janus Mesoporous Nanoparticle with Tunable Amphiphilicity. J. Am. Chem. Soc. 2018, 140, 10009-10015.

(47) Li, T. T.; Liu, Y.; Qi, S. C.; Liu, X. Q.; Huang, L.; Sun, L. B. Calcium Oxide-Modified Mesoporous Silica Loaded onto Ferriferrous Oxide Core: Magnetically Responsive Mesoporous Solid Strong Base. J. Colloid Interface Sci. 2018, 526, 366-373.

(48) Kuwahara, Y.; Kaburagi, W.; Osada, Y.; Fujitani, T.; Yamashita, H. Catalytic Transfer Hydrogenation of Biomass-Derived Levulinic Acid and Its Esters to $\gamma$-Valerolactone over $\mathrm{ZrO}_{2}$ Catalyst Supported on SBA-15 Silica. Catal. Today 2017, 281, 418-428.

(49) Zhang, B.; Xie, F.; Yuan, J.; Wang, L.; Deng, B. MeerweinPonndorf-Verley Reaction of Acetophenone over $\mathrm{ZrO}_{2}-\mathrm{La}_{2} \mathrm{O}_{3} / \mathrm{MCM}$ 41: Influence of Loading Order of $\mathrm{ZrO}_{2}$ and $\mathrm{La}_{2} \mathrm{O}_{3}$. Catal. Commun. 2017, 92, 46-50.

(50) Scholz, J.; Walter, A.; Ressler, T. Influence of MgO-Modified SBA-15 on the Structure and Catalytic Activity of Supported Vanadium Oxide Catalysts. J. Catal. 2014, 309, 105-114.

(51) Park, D.; Kim, J.; Kim, T. Nonthermal Plasma-Assisted Direct Conversion of Methane over $\mathrm{NiO}$ and $\mathrm{MgO}$ Catalysts Supported on SBA-15. Catal. Today 2018, 299, 86-92.

(52) Zhao, Y.; Li, J.; Zhao, L.; Zhang, S.; Huang, Y.; Wu, X.; Wang, $\mathrm{X}$. Synthesis of Amidoxime-Functionalized $\mathrm{Fe}_{3} \mathrm{O}_{4} @ \mathrm{SiO}_{2}$ Core-Shell Magnetic Microspheres for Highly Efficient Sorption of U(VI). Chem. Eng. J. 2014, 235, 275-283.

(53) Han, J.; Lu, S.; Jin, C.; Wang, M.; Guo, R. $\mathrm{Fe}_{3} \mathrm{O}_{4} / \mathrm{PANI} / \mathrm{m}-$ $\mathrm{SiO}_{2}$ as Robust Reactive Catalyst Supports for Noble Metal
Nanoparticles with Improved Stability and Recyclability. J. Mater. Chem. A 2014, 2, 13016-13023.

(54) Gawande, M. B.; Branco, P. S.; Varma, R. S. Nano-Magnetite $\left(\mathrm{Fe}_{3} \mathrm{O}_{4}\right)$ as a Support for Recyclable Catalysts in the Development of Sustainable Methodologies. Chem. Soc. Rev. 2013, 42, 3371-3393.

(55) Baig, R. B. N.; Varma, R. S. Magnetically Retrievable Catalysts for Organic Synthesis. Chem. Commun. 2013, 49, 752-770.

(56) Baig, R. B. N.; Varma, R. S. Organic Synthesis via Magnetic Attraction: Benign and Sustainable Protocols Using Magnetic Nanoferrites. Green Chem. 2013, 15, 398-417.

(57) Cychosz, K. A.; Guillet-Nicolas, R.; Garcia-Martinez, J.; Thommes, M. Recent Advances in the Textural Characterization of Hierarchically Structured Nanoporous Materials. Chem. Soc. Rev. 2017, 46, 389-414.

(58) Thommes, M.; Kaneko, K.; Neimark, A. V.; Olivier, J. P.; Rodriguez-Reinoso, F.; Rouquerol, J.; Sing, K. S. Physisorption of Gases, with Special Reference to the Evaluation of Surface Area and Pore Size Distribution (IUPAC Technical Report). Pure Appl. Chem. 2015, 87, 1051-1069. 